\title{
Cultural model theory in cognitive anthropology: recent developments and applications
}

\author{
Giovanni Bennardo • Victor C. de Munck
}

Published online: 12 March 2020

(C) Springer Nature Singapore Pte Ltd. 2020

\section{Introduction}

One of the most noteworthy developments in cognitive anthropology, if not in anthropology as a whole, is the proposal to adopt Cultural Model Theory (CMT) for investigating culture (Shore 1996; Strauss and Quinn 1997; Bennardo 2018; De Munck and Bennardo 2019). The foremost assumptions of this theory regard the concept of culture as mental knowledge shared by members of a community. A community need not be territorially based, but any social group that recognizes itself as such and espouses a shared identity, including groups that are internet based. In addition, this constitutive knowledge is organized into a number of mental models that are called 'cultural models' because as the components of culture they must also be shared.

The adoption of CMT entails a methodological path as first proposed and described by Bennardo and de Munck (2014), in which both qualitative and quantitative data acquisition and analyses co-exist in a crossfeeding interaction. At the same time, both types of

Special Issue of the Journal of Cultural Cognitive Science.

G. Bennardo $(\bowtie)$

Northern Illinois University, DeKalb, USA

e-mail: bennardo@niu.edu

V. C. de Munck $(\bowtie)$

Vilnius University, Vilnius, Lithuania

e-mail: demunckv@gmail.com data are rooted in ethnography as a fundamental and necessary molding background.

CMT is not a completely new approach to culture in anthropology, scholars researching cultural models have been doing so for more than three decades (e.g., Holland and Quinn 1987). However, a separation between research projects privileging either a qualitative approach-based on the acquisition and analysis of linguistic data-or a quantitative approachbased on cognitive tasks for data acquisitionemerged very early. This division has delayed the full development of the field and reduced its potential to be an effective presence in anthropology and cognitive science.

We are convinced that, as of recently, CMT has undergone new developments and a theoretical and methodological coherence has emerged that could remedy the unnecessary divisiveness experienced so far. It is mainly for this reason that we, Giovanni Bennardo and Victor C. de Munck, are guest editing a Special Issue of the Journal of Cultural Cognitive Science entitled "Cultural Model Theory in Cognitive Anthropology: Recent Developments and Applications" about contemporary research conducted in cognitive anthropology and specifically about the use and the application of CMT in research across the world.

The Special Issue starts with a contribution by Victor C. de Munck in which he discusses how CMT contributes to dissipate some of the criticisms advanced by extensionist and radical extensionist 
theories of cognition. Contributions by a number of senior scholars follow. Giovanni Bennardo offers an exemplary implementation of the tri-partite methodology required to investigate cultural models. He presents the results of an impressive number of analyses conducted on ethnographic, linguistic and cognitive data. The Tongan (Polynesian) cultural model of nature he discovers is validated by a final consensus analysis. Edward D. Lowe introduces the complex interplay between arousal, hedonic and intersubjective dimensions in the construction of local models of emotion in the Pacific. Douglas W. Hume explains how decision making about swidden farming in Belize is rooted in the transmission of knowledge within very close kinship groups. Renatas Berniunas, explores the cultural model of morality among Mongolians and how their conceptions of morality differ significantly from the canonical meaning in western psychology.

A few young scholars are also included in the special issue. Lawrence $\mathrm{T}$. Monocello provides a comparative analysis of male body image between the US and South Korea. In the US he notes that fat is conceived in terms of a cultural model of "healthism" where the fat person is at fault for not taking care of themselves, thus inviting a moral judgement by other. In South Korea fat is perceived through a cultural model referred to as "lookism" which lacks a moral component by viewing fat as a physical flaw often rooted in biology rather than psychology. In South Korea fat can be remedied by external means such as surgery or diet plans, and is not indicative of moral slackness. Nadia Biletska explores a changing Ukrainian society and how a number of cultural models of society she discovers patterns with generational changes. Finally, John H. Hood delves into Burmese culture in a tri-partite sample of the population of Burmese living in the US. His findings problematize a simplistic interpretation of the concept of democracy as used by three generations of Burmese and by the general American public.

The contributors to this Special Issue not only augment and expand what CMT contributes to the contemporary landscape of anthropological theory, but they also take us on a ride around the world to discover and understand insightful morsels of native, local thinking practices. The effervescence that transpires from these contributions witnesses to the valuable and long-lasting effect that CMT is bringing to (cognitive) anthropology. We are convinced that this Special Issue can potentially generate an enduring research agenda whose findings will enrich greatly not only anthropology, but also and centrally other sister disciplines such as sociology, psychology and (cultural) cognitive science.

\section{References}

Bennardo, G. (2018). Cultural models theory. Anthropology News website. https://doi.org/10.1111/AN.919. (July 17, 2018).

Bennardo, G., \& De Munck, V. C. (2014). Cultural models: Genesis, methods, and experiences. Oxford: Oxford University Press.

De Munck, V. C., \& Bennardo, G. (2019). Disciplining culture: A sociocognitive approach. Current Anthropology, 60(2), 174-193.

Holland, D., \& Quinn, N. (Eds.). (1987). Cultural models in language and thought. Cambridge: Cambridge University Press.

Shore, B. (1996). Culture in mind: Cognition, culture, and the problem of meaning. Oxford: Oxford University Press.

Strauss, C., \& Quinn, N. (1997). A cognitive theory of cultural meaning. Cambridge: Cambridge University Press.

Publisher's Note Springer Nature remains neutral with regard to jurisdictional claims in published maps and institutional affiliations. 